\title{
On-line pump for very low power heating or cooling system
}

\author{
Zbigniew Goryca ${ }^{1}$, Grzegorz Peczkis ${ }^{2}$, Tomasz Synowiec ${ }^{3}$ and Piotr Wiśniewski* \\ ${ }^{1}$ Kielce University of Technology, Department of Building Physics and Renewable Energy, \\ Tysiąclecia Państwa Polskiego 7, 25-314 Kielce, Poland \\ ${ }^{2}$ Silesian University of Technology, Department of Power Engineering and Turbomachinery, \\ Konarskiego 18, 44-100 Gliwice, Poland \\ ${ }^{3}$ WIROMET S.A., Wyzwolenia 27, 43-190 Mikołów, Poland
}

\begin{abstract}
The article presents the concept of a new circulation pump for low power heating or cooling system, dedicated to systems where it is necessary to ensure a slight liquid flow during periods of operation at a significantly low efficiency of the systems. The assumption for the construction of the new pump was the possibility of its installation in the pipeline axis. The proposed prototype design includes the application of a patented solution to relieve the axial force acting in a flow system $[1,2]$. Additionally, a new permanent magnet DC motor designed and manufactured for this pump was used. The design of the pump takes into account the requirement of maximum silence, which results from its intended use in close proximity to human habitation. The design of the pump has been tested numerically. The results of numerical tests are presented. The pump was made in the rapid prototyping technique in a $3 \mathrm{D}$ printer. The pump was built into a dedicated test stand with measuring instruments verified in terms of the quality of measurements. A series of measurements was made on the basis of which the flow characteristics of the pump were determined. During the research, risks for the operation of the new structure were identified, which will be taken care of in a further stage of the research, and the structure, after removing the defects, will be directed to production [3].
\end{abstract}

\section{Introduction}

The heating / cooling medium circulation pumps for individual applications available on the market, especially in district heating, constitute a wide range of products. Dominating devices with an electric drive motor operating directly in the pumped medium. The motor is rarely separated from the pump flow system due to the significant cost of the gland packing, maintenance-free, for the entire structure [4]. An important gap in the series of types, indicated by a domestic producer of complete heating systems, is a pump with a low head and low flow, which protects the circulation systems against damage during periods of its shutdown. Two practical failure-generating cases are particularly indicated. The first is the

\footnotetext{
*Corresponding author: piotr.wisniewski@polsl.pl
} 
strong local heating of the elements of solar systems, shut down during the summer period when the demand for heat is insufficient. Second, the deposition of mineral particles and the effects of corrosion on components immersed in the liquid, which are not moved, and through which the liquid does not flow. The flow parameters were specified by the manufacturer, who also set the task of minimizing the dimensions of the pump and the possibility of including it in the axis of the pipeline, the so-called on-line [5]. The presented construction and research results are a pump that fulfills the assumptions of operation in systems that are periodically shut down.

\section{Pump design}

The design of the impeller of the flow system was based on the known algorithm for designing centrifugal centrifugal pumps available in the literature [6,7]. It has been proposed to reverse the direction of the rotor in relation to the drive motor, i.e. to place the inflow to the pump rotor from the side of the driving motor and to make a new motor that, when seated on the liquid supply channel to the pump, will rotate directly with the rotor [8]. The impeller therefore does not have a drive shaft, the function of which is taken over by the pump's influence channel [9]. The pump discharge channel has been divided into two streams and, after changing the direction from radial to axial, it is connected in the discharge stub pipe. [10] The authors of the article successfully tested and applied such a solution to the previously implemented mining pump. The three-phase alternating current electric motor with permanent magnets presented in the construction was designed and made by professor Zbigniew Goryca. In addition, a small electronic system powered by DC voltage was made, from which the 3-phase voltage was supplied to the pump motor. The frequency of the alternating voltage on the basis of which the pump rotational speed was calculated using an oscilloscope was later measured on the 3-phase voltage. The constant magnetic force generated by the motor, independent of the applied voltage, keeps the rotating system suspended in the slide bearings in balance with respect to possible axial displacements $[11,12]$. The displacement of the rotating system along the pump axis at rest meets the resistance of the magnetic force. During pump operation, the rotor system creates an axial force whose direction is opposite to the flow direction of the pumped liquid at the inlet to the rotor. [13] This force is the result of an imbalance in the pressure distribution acting between the stationary fuselage and the rotating walls of the cover plate and the rotor support plate. The figure shows schematically the pressure imbalance acting in the described spaces on the flow system, resulting in an axial force. In order to balance the resulting axial force, a proprietary, patented oblique gap solution was used, which creates a quasi-bearing operating on the pumped liquid and finally provides friction-free. This solution is depicted on Figure 1. 
Fig. 1. Pump final design

\section{Numerical Analysis}

The geometric model of the pump was subjected to numerical analysis in order to verify the design assumptions within the flow system. For this purpose, using ANSYS Fluent software, a numerical polyhedral mesh consisting of about 2 million elements was generated. The mesh was densified in the boundary layer area to provide a $y+$ value of about 1 , the successive cell growth rate in the layer is 1.2 , which allows high quality results to be obtained using a reasonable number of elements. The turbulent effects of the flow were modeled using the k$\omega$ shear-stress transport (SST) model proposed by Mentner $[14,15]$. The remaining grid parameters were determined on the basis of data available in the literature for modeling water flows in turbines [16]. It was assumed that the flow is isothermal and the water temperature is $25^{\circ} \mathrm{C}$. The conditions defining the total pressure at the inlet and the static pressure of the fluid at the outlet from the system were used, the condition defining the rotational speed of the rotor was added in the rotor part, the calculations were carried out in a steady state.

Numerical calculations were performed for various useful pump power. Figure 2 shows the characteristics of the system as a function of the flow rate at constant power on the pump shaft. The efficiency presented on Figure 2 does not include the gearing and electric engine efficiency, it is computed as follows:

$$
\eta=\frac{H Q}{P_{m}}
$$

where $\eta$ is efficiency, $H$ is lifting, $Q$ is volume flow rate and $P_{m}$ is mechanical power. The results of the numerical analysis are in line with the pump design assumptions and are a good reference to experimental work. 


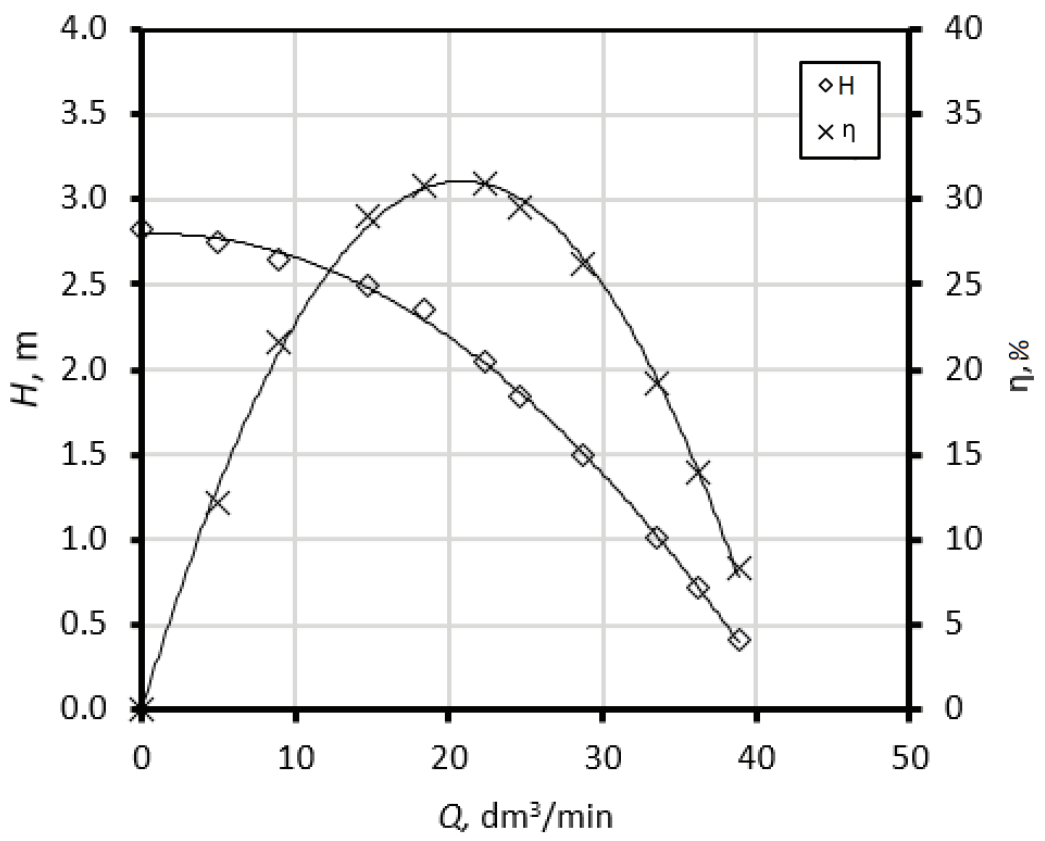

Fig. 2. Pump lifting and efficiency characteristic based on the numerical study

\section{$424,26 \mathrm{~V}$ experimental study}

The constructed pump was subjected to numerical tests at the 3D construction stage. Further work was aimed at printing individual pump elements from plastic and developing a technique for machining the print elements in order to give them matching dimensions. The $3 \mathrm{D}$ printout is burdened with surface unevenness, and the external, overall dimensions make it impossible to fit precise elements, e.g. bearing elements. In practice, it is possible to mount the bearings by pressing, but they deform and change other dimensions of the printed element. The metal ring visible in the photo into which the pump housing is screwed enables dimensionally repeatable mounting in the jaws of the machine tool and precise machining in order to adjust, for example, the fitted winding of the motor, both the stator and the rotor. The individual elements of the engine and the power cables led out of the fuselage were filled with epoxy resin, the composition of which does not chemically react with the material used for 3D printing. After the filling was made and it dried, and it was re-machined, it was tested for the separation of the electrical system from the pumped liquid. The pump tests were performed on the stand shown on figure 3 . The measuring system was made of instruments subjected to calibration in the laboratory. 


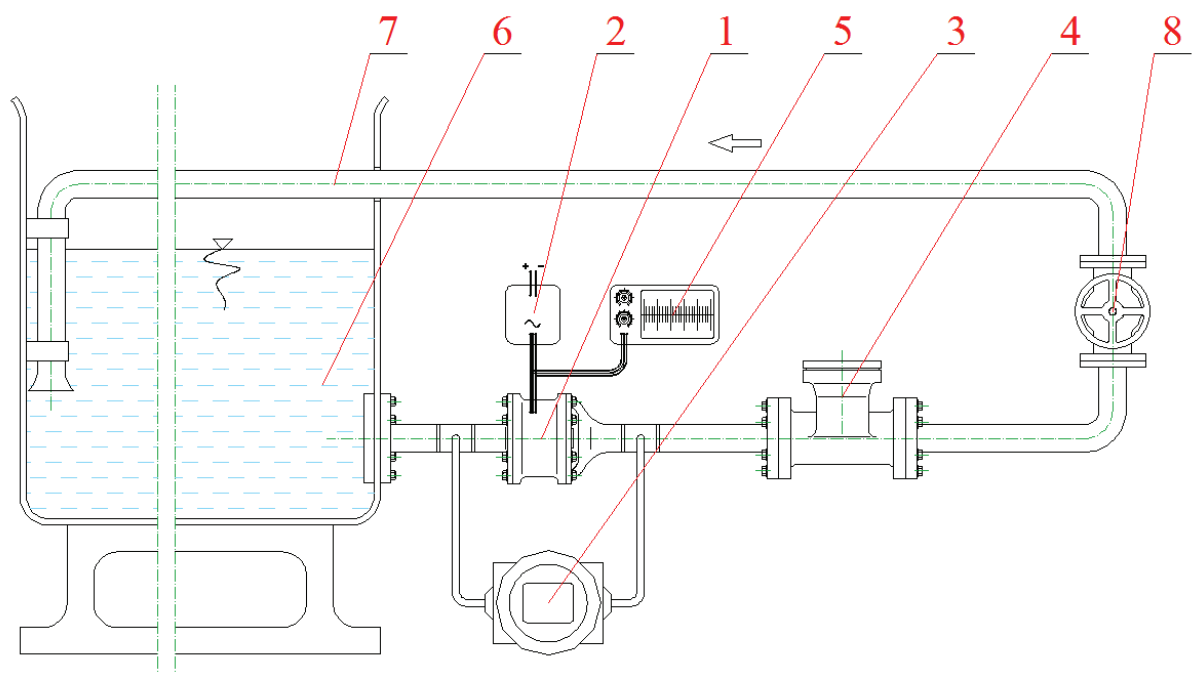

Fig. 3. Scheme of the measuring system. Positions: 1-tested pump 2-power supply system, generation of alternating current from direct current 3- differential manometer 4-electromagnetic flowmeter 5oscilloscope 6- circulation liquid tank 7-circulation pipeline system 8 - throttle valve

The pressure sensor was checked on a hydraulic press, the electromagnetic flow meter was verified for the correctness of indications by the volumetric method. The oscilloscope attachment used for electrical measurements was not marked. It was used to determine the actual rotational speed of the pump rotating assembly. Further the pump lifting characteristics was designated for different voltage, see figure 4 . The pressure behind the impeller and in front of the steering wheel on the discharge of the pump was measured in order to reduce the amount of losses to the discharge port. The characteristic of the pump head and the pressure drop between the pump's suction port and the measurement point behind the impeller, presented on figure 5 , are consistent with the expected energy parameters of the pump. The following characteristics are systematized depending on the DC supply voltage of the system generating the 3-phase alternating current supplying the motor.

During the tests, it was found that the pump, together with the electric motor and the electronic system for converting the DC voltage of the system supply to AC voltage, works with unsatisfactory efficiency close to $20 \%$. Observation of the pump operation and additional measurements performed showed insufficient magnetic force of the motor, which did not keep the rotating assembly in the balance of axial forces. Also, the first prepared variant of the oblique slot, tested computationally, did not faithfully reflect the assumptions in practice. This resulted in a slight displacement of the rotating assembly and its elements rubbing against the fuselage elements during operation. Hence the unsatisfactory efficiency obtained in the first experiments. Further works are aimed at eliminating losses by rebuilding the bearing system. Due to the high degree of saturation of the structure with innovative solutions, this should not be seen as a disqualification of the structure, and the currently obtained results of the prototype tests as an introduction to a new, stable design solution in line with the previous assumptions. 


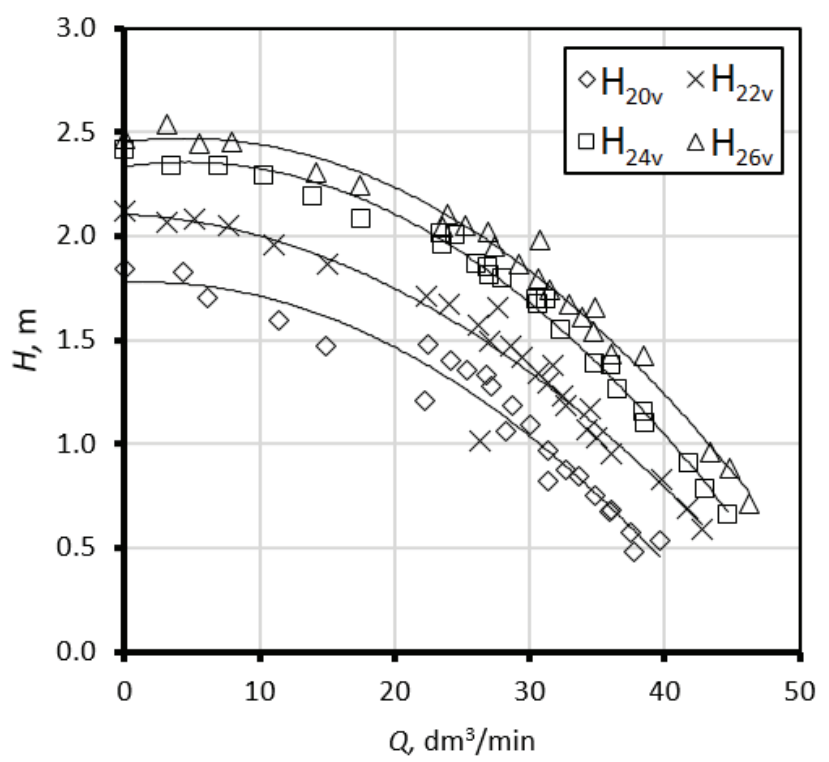

Fig. 4. Pump lifting characteristics intended at the laboratory stand for successive supply voltages of $20,22,24,26 \mathrm{~V}$

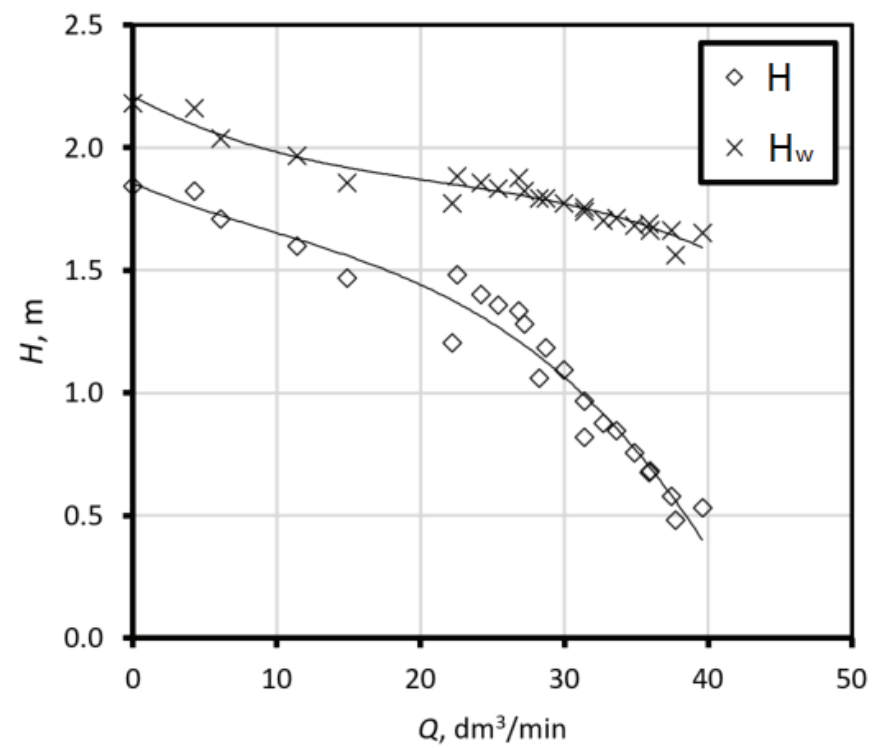

Fig. 5. Comparison of the pressure measurement behind the impeller $H_{-} w(Q)$ to the pressure drop $H$ (Q) realized on the pump for the supply voltage of $20 \mathrm{~V}$

\section{Summary}

The course of construction works, numerical tests, execution and laboratory tests presented in the article confirmed in practice the achievement of the assumed useful lifting height met at the desired volumetric flow rates. The multitude of innovative solutions used in one structure is the reason for the need to improve the presented pump. The conducted works 
require continuation prior to production improvement of the efficiency of the centrifugal pump unit, the motor and the three-phase DC current generation system up to the values obtained in numerical calculations. In particular, the shape of the double-stream channel requires optimization, which is confirmed by the comparison of the pressure drop across this element presented in the article to the characteristic of the effective head of the pump. These works are ongoing and their effect will be reflected in the near future. The success of the task performed by the presented pump at the present stage does not allow doubting the success of the continued work.

\section{References}

1. Korczak A. Badania układów równoważących napór osiowy w w wielostopniowych pompach odśrodkowych. Pierwsze ed. Gliwice: Wydawnictwo Politechniki Śląskiej; (2005).

2. Альбінович МВ. Щелевые Уплотнения Сумы: Изд-во Сумского; (2005).

3. Ostojic P. Pumps and circular economy. World Pumps. 2016 Volume (2016), Issue 1: p. 30-33.

4. Waldemar J. Pompy Wirowe Warszawa: PWN; (2001).

5. Jęrdal W. Efektywne energetycznie układy pompowe. I ed. Warszawa: Oficyna Politechniki Warszawskiej; (2018).

6. Palgrave R. Centrifugal pump basics. Troubleshooting Centrifugal Pumps and their Systems. (2020): p. 13-60.

7. Wenjie Zhou YWCLWZGW. Analysis of fluid-induced force of centrifugal pump impeller with compound whirl. Alexandria Engineering Journal. (2020): p. 4247-4255.

8. Nader Moazami KFMKNGSKJHAMSLDJHRCS. Axial and centrifugal continuousflow rotary pumps: A translation from pump mechanics to clinical practice. The Journal of Heart and Lung Transplantation. (2013) Volume 32, Issue 1,: p. 1053-2498.

9. Younes YK. A revised design of circular hydrostatic bearings for optimal pumping power. Tribology International. (1993) Volume 26, Issue 3: p. 195-200.

10. Bin Hu SXRZWHLLHZZHL. Investigation on advanced heat pump systems with improved energy efficiency. Energy Conversion and Management. (2019): p. 161-170.

11. Zhichao Zou FWZYRTRXHL. Impeller radial force evolution in a large doublesuction centrifugal pump during startup at the shut-off condition. Nuclear Engineering and Design. (2016) Volume 310: p. 410-417.

12. Kalinichenko P, Suprun A. Effective Modes of Axial Balancing of Centrifugal Pump Rotor. In XIIIth International Scientific and Engineering Conference "HERVICON2011"; (2012); Sumy: Procedia Engineering.

13. Bin Hu HLRZWHLZZSW. A high-efficient centrifugal heat pump with industrial waste heat recovery for district heating. Applied Thermal Engineering. (2017) Volume 125: p. 359-365.

14. Menter FR. Two-equation Eddy-Viscosity Turbulence Models for Engineering Applications. AIAA Journal. (1994): p. 1598-1605.

15. ANSYS Fluent Theory Guide, (2021)R1. [Online]. [cited 2021 July 1.

16. Peczkis G, Wiśniewski P, Zahorulko A. Experimental and Numerical Studies on the Influence of Blade Number in a Small Water Turbine. Energies. (2021). 